\title{
Nasal carriage of methicillin-resistant Staphylococcus aureus (MRSA) among undocumented migrants and uninsured legal residents in Amsterdam, the Netherlands: a cross-sectional study
}

\author{
E. van Dulm ${ }^{1 *+}$ D, S. Klok ${ }^{2+}$, A. Boyd ${ }^{1,3}$, I. K. Joore ${ }^{4}$, M. Prins ${ }^{1,5}$, A. P. van Dam ${ }^{1,6}$, G. A. Tramper-Stranders ${ }^{2}$ and
} Y. T. H. P. van Duijnhoven ${ }^{1}$

\begin{abstract}
Background: Nasal carriage of methicillin-resistant Staphylococcus aureus (MRSA) is associated with an increased risk of infection. Colonization with MRSA is observed in $<1 \%$ of the general Dutch population. Increased risk for MRSA carriage is known to occur in several key groups, one of which is asylum seekers. However, little is known about MRSA carriage among undocumented migrants and uninsured legal residents. This study aimed to determine the prevalence of nasal MRSA carriage among these groups in Amsterdam, the Netherlands.

Methods: In this cross-sectional study, between October 2018 and October 2019, undocumented migrants and uninsured legal residents aged 18 years or older who were able to understand one of the study languages were recruited at an NGO health care facility in Amsterdam, the Netherlands, for general practitioner (GP) consultations. Participants were asked questions on demographics, migration history, antibiotic use and other possible risk factors for MRSA carriage and were screened for nasal MRSA carriage by selective culturing e-swabs. Characteristics of MRSA-negative and MRSA-positive participants were compared using univariable logistic regression analysis with Firth's correction.

\footnotetext{
* Correspondence: evdulm@ggd.amsterdam.nl

${ }^{\dagger}$ E. van Dulm and S. Klok contributed equally to this work.

'Department of Infectious Diseases, Public Health Service Amsterdam, Nieuwe Achtergracht 100, 1018WT Amsterdam, the Netherlands

Full list of author information is available at the end of the article
}

(c) The Author(s). 2020 Open Access This article is licensed under a Creative Commons Attribution 4.0 International License, which permits use, sharing, adaptation, distribution and reproduction in any medium or format, as long as you give appropriate credit to the original author(s) and the source, provide a link to the Creative Commons licence, and indicate if changes were made. The images or other third party material in this article are included in the article's Creative Commons licence, unless indicated otherwise in a credit line to the material. If material is not included in the article's Creative Commons licence and your intended use is not permitted by statutory regulation or exceeds the permitted use, you will need to obtain permission directly from the copyright holder. To view a copy of this licence, visit http://creativecommons.org/licenses/by/4.0/ The Creative Commons Public Domain Dedication waiver (http://creativecommons.org/publicdomain/zero/1.0/) applies to the data made available in this article, unless otherwise stated in a credit line to the data. 


\begin{abstract}
(Continued from previous page)
Results: Of the 3822 eligible patients, 760 were screened for nasal MRSA carriage (19.9\%). Of the 760 participants, over half were male (58\%; 442/760) and originated mainly from Africa (35\%; 267/760), Asia (30\%; 229/760) and North or South America (30\%; 227/760). In total, 705/760 participants (93\%) were undocumented migrants and 55/760 (7\%) were uninsured legal residents of Amsterdam. The overall prevalence of nasal MRSA carriage was $2.0 \%(15 / 760)(95 \% \mathrm{Cl}$ 1.1 to $3.2 \%)$, with no difference between undocumented migrants (14/705) (2.0,95\%Cl 1.1 to 3.3\%) and uninsured legal residents (1/55) (1.8, 95\%Cl 0.1 to 9.7\%). Genotyping showed no clustering of the 15 isolates. MRSA carriage was not associated with sociodemographic, migration history or other possible risk factors. Nevertheless, this study had limited power to detect significant determinants. Three participants $(3 / 15 ; 20 \%)$ harbored Panton-Valentine leukocidin (PVL)positive isolates.

Conclusion: Even though our study population of undocumented migrants and uninsured legal residents had a higher prevalence of nasal MRSA carriage compared to the general Dutch population, the prevalence was relatively low compared to acknowledged other high-risk groups.
\end{abstract}

Keywords: MRSA, Nasal carriage, Undocumented migrants, Uninsured legal residents

\section{Background}

Staphylococcus aureus is a commensal bacterium, but frequently causes clinically important nosocomial or community-acquired infections [1]. During infection with methicillin-resistant $S$. aureus (MRSA), treatment options are limited. Even though the number of MRSA infections is still relatively low in many Western and Northern European countries, approximately 150,000 infections of MRSA occur each year in the European Union, accounting for an estimated 7000 deaths annually [2].

Nasal carriage of S. aureus in general is associated with an increased risk of MRSA infection [3, 4]. Consequently, the Netherlands has taken an aggressive approach to prevent the spread of MRSA in those with MRSA carriage. As part of the Dutch MRSA search and destroy policy, all known MRSA carriers, as well as their household and in-hospital contacts, and all patients who have been admitted to foreign hospitals for more than $24 \mathrm{~h}$ in the previous $2 \mathrm{~m}$ are isolated at hospital admission [5, 6]. Isolation is prolonged until screening cultures for MRSA are negative or MRSA carriage is eradicated. Coupled with the general reluctance of prescribing antibiotics among Dutch physicians [7], the prevalence of MRSA carriage is $<0.2 \%$ of new hospital admissions in the Netherlands $[8,9]$.

MRSA carriage is observed in $<1 \%$ of the general Dutch population [5], yet certain groups are known to have a higher prevalence. For instance, a recent study from the Netherlands has shown that $10 \%$ of asylum seekers were carriers of MRSA [10]. This prevalence falls in line with a recent systematic review and meta-analysis among migrants in Europe in which a pooled 8\% prevalence of MRSA carriage was estimated [11]. Nevertheless, other conducted studies in similar settings have reported widely varying prevalences, with a Norwegian study reporting MRSA carriage in $0.74 \%$ of asylum seekers [12] and one Finnish study reporting MRSA carriage in $21 \%$ of asylum seekers and refugees [13]. Part of this variation could be due to the variation in the countries of origin of migrants included in these studies.

Undocumented migrants (including rejected asylum seekers, migrants with expired visa and 'directly undocumented migrants', i.e. those who bypassed the asylum procedure) and uninsured legal residents are thought to represent a considerable fraction of migrants residing in the Netherlands, yet the exact proportion is unknown. Multiple international studies on immigration and the impact of immigration policies have shown an association between undocumented migration and poorer health outcomes [14-16]. In particular, the prevalence of infectious diseases (e.g. human immunodeficiency virus (HIV), hepatitis B virus (HBV), hepatitis $\mathrm{C}$ virus ( $\mathrm{HCV}$ ) and tuberculosis (TB)) tends to be higher among homeless individuals and undocumented migrants [17-21]. However, little is known about the proportion of MRSAcarriers among undocumented migrants and uninsured legal residents in the Netherlands. These individuals are known to live in more difficult socioeconomic situations (e.g. crowded living conditions) [22, 23], which could make them more vulnerable to inadequate care and possibly at higher risk for MRSA carriage. To the best of our knowledge, the prevalence of MRSA carriage in this population has not yet been studied. This study aimed to determine the prevalence of nasal MRSA carriage among undocumented migrants and uninsured legal residents in Amsterdam, the Netherlands.

\section{Methods}

\section{Study design, setting and population}

A cross-sectional study was designed to evaluate the prevalence of HBV, HCV, HIV and MRSA carriage in individuals seeking care at Kruispost, a low-threshold care facility for undocumented migrants and (Dutch) 
homeless and uninsured individuals. A sample of 1000 participants was intended to be recruited from patients visiting Kruispost for an appointment with a general practitioner (GP) during a one-year period. We based sample size on the capacity of Kruispost to recruit participants in a 12-month time span (i.e. convenience sample). Between October 2018 and October 2019, visitors aged 18 years or older who were able to understand one of the study languages (Dutch, English, French, Spanish, Arabic and Portuguese) were invited to participate.

Prior to June 20, 2019, we excluded patients originating from countries within the European Union (EU) and/or European Economic Area (EEA) who did not possess a citizen service number (CSN), since treatment could not be reimbursed by the central administration office (CAK)regulation during that time. The CAK is a public service provider that carries out regulations and translates legislations on behalf of the government. CAK-regulation reimburses medical treatment for uninsurable individuals under specific circumstances. As of June 20, 2019, this reimbursement regulation was extended to include individuals originating from countries within the EU or EEA without a CSN and thus after this date, these patients were also invited to participate.

In this report, we provide results on the MRSA screening component of the study. Therefore, only participants with an MRSA screening result were included in the analysis.

\section{Study procedures}

After GP consultation, patients were invited to participate in the study. Eligible patients were provided with study information and if willing to participate, gave oral informed consent. Patients who declined to participate were asked to complete a short questionnaire on demographics and reason(s) for non-participation. All participants were offered an incentive (a ticket for public transportation, socks, toothbrush, shampoo or disinfecting hand gel).

Participants completed two questionnaires: the first filled out together with a research associate (including only information on risk factors for $\mathrm{HBV} / \mathrm{HCV}$ infection to determine eligibility for $\mathrm{HBV} / \mathrm{HCV}$ screening) and the second self-administered (including all other information). Information obtained from the questionnaires included sociodemographic variables (age, sex, country of birth, educational level), migration history (year of leaving country of origin, year of arrival in the Netherlands, way of entering the Netherlands, housing situation, the number of housemates they currently live with), antibiotic use (current use and use in the past $6 \mathrm{~m}$ ) and other variables on potential risk factors (whether or not they had been abroad for more than $24 \mathrm{~h}$ in the past 6 $\mathrm{m}$, whether they have ever been admitted or treated in a foreign hospital, had surgery abroad, had a blood transfusion, had paid or had been paid for sex, and injected drugs).

On the day of informed consent, a nasal swab was taken by a research assistant to be screened for MRSA. All positive MRSA diagnoses were added to the electronic health record dossier (EHR) of Kruispost participants to inform healthcare providers in the event of (future) referral to secondary care. Since treatment of MRSA carriage is not indicated outside of hospital settings, we decided not to inform patients of their MRSA status. Participants were informed, however, that their MRSA status would be added to their EHR in case of a positive test.

\section{Laboratory detection}

Collected e-swabs (Copan, Brescia, Italy) were sent to the laboratory of the Public Health Service of Amsterdam by mail at the end of the day of sample collection. Transport time was $24-48 \mathrm{~h}$ by mail. The detection of MRSA was done according to the NVMM (Dutch Society for Medical Microbiology) guidelines for laboratory detection of highly-resistant microorganisms [24]. In brief, culture for MRSA was done by overnight enrichment in broth containing $6 \% \mathrm{NaCl}$, followed by subculture on selective chromogenic plates (CHROMID MRSA, Biomerieux, Marcy-l'Étoile, France), which were read after 24 and $48 \mathrm{~h}$. All cultures were done at $36^{\circ} \mathrm{C}$. S. aureus strains were identified by Maldi-TOF MS (Bruker, Massachusetts, United States of America). MRSA phenotype was confirmed by oxacillin E-test (BioMerieux, Marcy l'Étoile, France) and a PBP2A agglutination test (Alere, Massachusetts, United States of America). Presence of the mecA gene was confirmed at the National Institute of Public Health and the Environment (RIVM) by PCR [25]. Isolates were assessed for the presence of Panton-Valentine leukocidin (PVL) gene by PCR [26], which is mainly observed in community-associated MRSA [27] and, in general, is a virulence marker associated with more severe skin and soft tissue infections. Typing of strains isolated in this study was done by Multi-Locus Variable Number Tandem Repeat Analysis (MLVA) as is done with all MRSA strains isolated in the Netherlands in the nationwide MRSA surveillance [28].

\section{Statistical analyses}

Sociodemographics, questions on foreign treatments and antibiotic use were presented by MRSA status. Years since leaving the country of origin and years since arrival in the Netherlands were calculated. Comparisons between groups were made using Fisher exact test for categorical data and by Mann-Whitney $U$ test for continuous data. Prevalence of MRSA carriage and its corresponding Clopper-Pearson 95\% confidence interval (CI) were 
calculated. Odds ratios (OR) comparing odds for MRSA carriage across levels of determinants, along with their $95 \% \mathrm{CI}$, were assessed using univariable logistic regression with Firth's correction. The small number of MRSApositive samples in our study precluded any multivariable analysis. The significance level was set at $p<0.05$. All analyses were conducted with Stata 15.1 (StataCorp., College Station, Texas, USA).

\section{Results}

\section{Participants}

In total, 4017 patients visited Kruispost during the inclusion period. Of them, 89/4017 (2\%) were aged $<18$ years and 106/4017 (3\%) were unable to understand one of the six study languages. In total, 3822/4017 (95\%) eligible patients remained. Of them, 1376 (36\%) were invited to participate, and 760 (19.9\%) were screened for nasal MRSA carriage. (Fig. 1). Supplementary Table 1 compares the characteristics of those who did versus those who did not participate (restricted to non-participants completing the short questionnaire on demographics). Participants more often originated from Africa and Asia and left their country of origin less recently than non-participants. Furthermore, non-participants were more often European citizens compared to study participants. Supplementary Table 2 shows the reasons for non-participation among patients who completed a short questionnaire on demographics (33\% of total non-participants).

Of those who participated, the median age was 40 years (interquartile range (IQR) 31-50) and 58\% (442/760) were men. 705/760 participants (93\%) were undocumented migrants and 55/760 participants (7\%) were uninsured legal residents of Amsterdam. Participants originated mainly from Africa (35\%; 267/760), Asia $(30 \% ; 229 / 760)$ and North or South America (30\%; 227/760) and the majority completed secondary school $(42 \% ; 320 / 760)$ or higher education $(36 \% ; 274 / 760)$. The ways of entering the Netherlands were diverse across participants, but most indicated arriving on a (now expired) tourist, working or student visa $(54 \% ; 406 / 760)$, being a rejected asylum seeker $(18 \% ; 135 / 760)$, or illegally crossing borders $(16 \%$; $117 / 760)$. Five percent of participants (38/760) reported current use of antibiotics and 25\% (186/760) being abroad for more than $24 \mathrm{~h}$ in the past $6 \mathrm{~m}$. Of participants, $36 \%$ (268/760) reported admission to a foreign hospital and $33 \%(254 / 760)$ had surgery abroad (Table 1$)$.

\section{Prevalence of and risk factors for nasal MRSA carriage}

A total of 15 participants were MRSA-positive for nasal carriage, resulting in an overall prevalence of $2.0 \%(95 \%$ CI 1.1 to $3.2 \%)$. This prevalence was comparable between undocumented migrants (14/705)

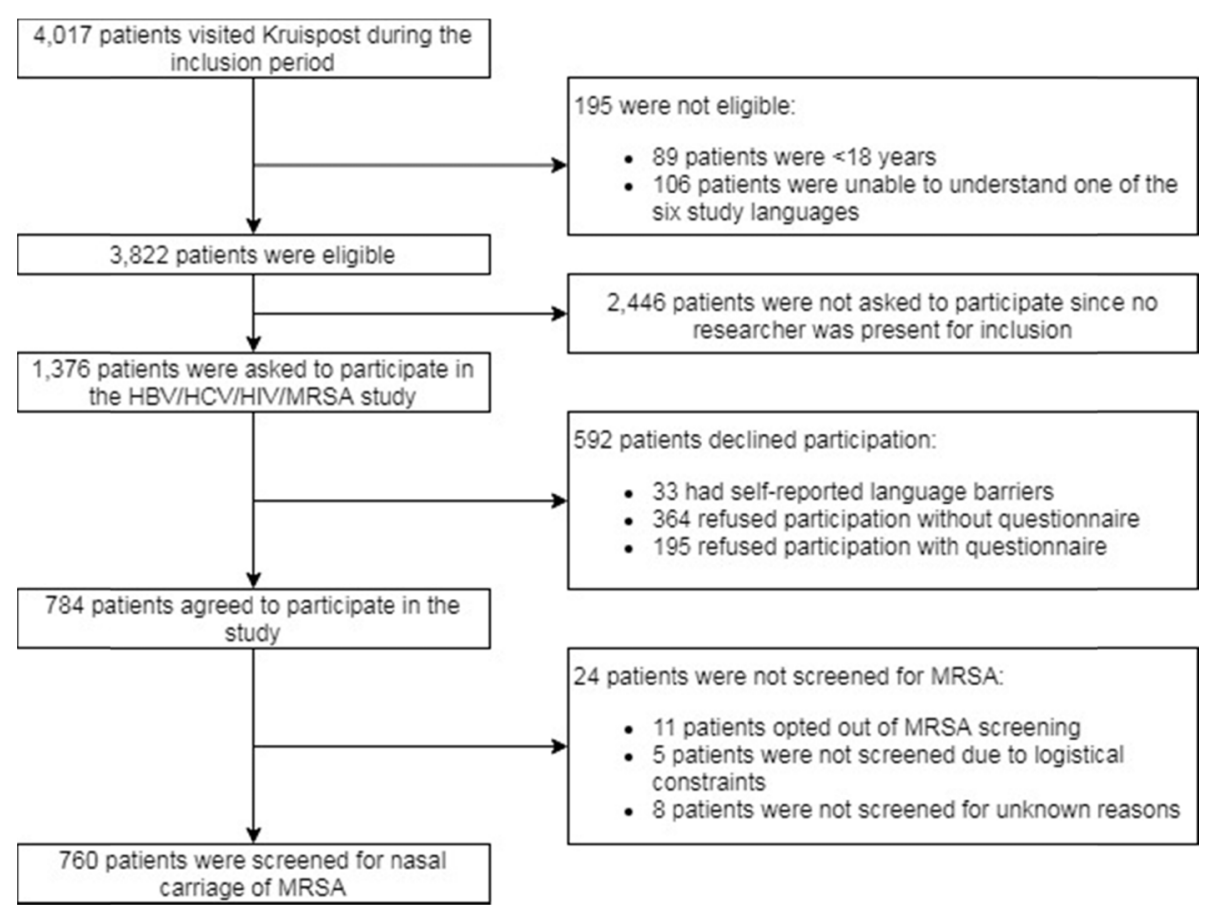

Abbreviations: HBV = Hepatitis B Virus; HCV = Hepatitis C Virus; HIV = Human Immunodeficiency Virus; MRSA = Methicillin-resistant Staphylococcus aureus'

Fig. 1 Recruitment strategy of MRSA screening offered to undocumented migrants attending Kruispost in Amsterdam, the Netherlands ( $N=4017)$. Abbreviations: HBV = Hepatitis B Virus; HCV = Hepatitis C Virus; HIV = Human Immunodeficiency Virus; MRSA = Methicillin-resistant Staphylococcus aureus' 
Table 1 Characteristics of undocumented migrants and uninsured legal residents $(N=760)$ and determinants of nasal MRSA carriage, in Amsterdam, the Netherlands, October 2018-October 2019 (univariable logistic regression analyses with Firth's correction)

\begin{tabular}{|c|c|c|c|c|c|c|c|c|}
\hline \multirow[b]{2}{*}{ Sociodemographic variables } & \multicolumn{2}{|c|}{ Total $(\boldsymbol{N}=760)$} & \multicolumn{2}{|c|}{$\begin{array}{l}\text { MRSA-negative } \\
\text { participants }(\boldsymbol{N}=745)\end{array}$} & \multicolumn{2}{|c|}{$\begin{array}{l}\text { MRSA-positive } \\
\text { participants }(\boldsymbol{N}=15)\end{array}$} & \multicolumn{2}{|c|}{$\begin{array}{l}\text { Univariable } \\
\text { associations }\end{array}$} \\
\hline & $n$ & $\%$ & $n$ & $\%$ & $N$ & $\%$ & $\mathrm{OR}$ & $95 \% \mathrm{Cl}$ \\
\hline \multicolumn{9}{|l|}{ Sex } \\
\hline Male & 442 & $58 \%$ & 431 & $58 \%$ & 11 & $73 \%$ & Ref & \\
\hline Female & 317 & $42 \%$ & 313 & $42 \%$ & 4 & $27 \%$ & 0.54 & $0.18-1.62$ \\
\hline Other & 1 & $0.1 \%$ & 1 & $0.1 \%$ & 0 & $0 \%$ & * & * \\
\hline Age in years, median (IQR) & 40 & $(31-50)$ & 40 & $(31-50)$ & 35 & $(32-48)$ & & \\
\hline \multicolumn{9}{|l|}{ Age, categorized } \\
\hline$<35$ years & 249 & $33 \%$ & 243 & $33 \%$ & 6 & $40 \%$ & Ref & \\
\hline $35-49$ years & 302 & $40 \%$ & 295 & $40 \%$ & 7 & $47 \%$ & 0.95 & $0.33-2.76$ \\
\hline $50-64$ years & 183 & $24 \%$ & 181 & $24 \%$ & 2 & $13 \%$ & 0.52 & $0.12-2.25$ \\
\hline$\geq 65$ years & 26 & $3 \%$ & 26 & $3 \%$ & 0 & $0 \%$ & 0.71 & $0.04-12.90$ \\
\hline \multicolumn{9}{|l|}{ Kruispost target population } \\
\hline Undocumented migrant & 705 & $93 \%$ & 691 & $93 \%$ & 14 & $93 \%$ & Ref & \\
\hline Uninsured legal resident & 55 & $7 \%$ & 54 & $7 \%$ & 1 & $7 \%$ & 1.31 & $0.24-7.21$ \\
\hline \multicolumn{9}{|l|}{ Region of birth } \\
\hline Europe & 36 & $5 \%$ & 36 & $5 \%$ & 0 & $0 \%$ & Ref & \\
\hline Asia & 229 & $30 \%$ & 222 & $30 \%$ & 7 & $47 \%$ & 2.46 & $0.14-44.01$ \\
\hline Africa & 267 & $35 \%$ & 261 & $35 \%$ & 6 & $40 \%$ & 1.81 & $0.10-32.89$ \\
\hline North/South America & 227 & $30 \%$ & 225 & $30 \%$ & 2 & $13 \%$ & 0.81 & $0.04-17.20$ \\
\hline \multicolumn{9}{|l|}{ Educational level } \\
\hline No school & 33 & $4 \%$ & 33 & $4 \%$ & 0 & $0 \%$ & Ref & \\
\hline Primary school & 129 & $17 \%$ & 125 & $17 \%$ & 4 & $27 \%$ & 2.40 & $0.13-45.74$ \\
\hline Secondary school & 320 & $42 \%$ & 314 & $42 \%$ & 6 & $40 \%$ & 1.38 & $0.08-25.13$ \\
\hline Higher education & 274 & $36 \%$ & 269 & $36 \%$ & 5 & $33 \%$ & 1.37 & $0.07-25.28$ \\
\hline
\end{tabular}

Migration history

Year of leaving country of origin, median (IQR)

2011 (2003-2016) 2011

(2003-2016)

2016

(2009-2016)

Year of leaving country of origin, categorized

$<2010$
$2010-2017$
$\geq 2018$

$$
\begin{aligned}
& 335 \\
& 329 \\
& 88
\end{aligned}
$$$$
335 \quad 45 \%
$$$$
32944 \%
$$$$
330
$$$$
45 \%
$$$$
44 \%
$$

Years since leaving country of origin, median (IQR)

Year of arrival in the Netherlands, median (IQR)

$$
8 \quad(3-16)
$$

2013 (2006-2017) 2013

$$
12 \%
$$

(2006-2017)

$\begin{array}{ll}5 & 33 \% \\ 8 & 53 \% \\ 2 & 13 \%\end{array}$

Ref

$1.59 \quad 0.54-4.69$

$1.74 \quad 0.38-7.89$

Year of arrival in the Netherlands

$<2010$
$2010-2017$
$\geq 2018$

$\begin{array}{llll}279 & 37 \% & 276 & 37 \% \\ 308 & 41 \% & 300 & 41 \% \\ 167 & 22 \% & 163 & 22 \%\end{array}$

Years since arrival in the Netherlands, median (IQR)

$5 \quad(2-13)$

6

(2-13)

Way of entering the Netherlands

Expired tourist/working/student visa
Rejected asylum seeker
EU citizen
Illegally crossing borders
Legally/other visa**/work

$\begin{array}{llll}406 & 54 \% & 398 & 54 \% \\ 135 & 18 \% & 133 & 18 \% \\ 40 & 5 \% & 39 & 5 \% \\ 117 & 16 \% & 113 & 15 \% \\ 37 & 5 \% & 37 & 5 \%\end{array}$

(3-10)

$0.98 \quad 0.93-1.04$

$2016 \quad(2012-2018)$

$\begin{array}{llll}3 & 20 \% & \text { Ref } & \\ 8 & 53 \% & 2.23 & 0.64-7.84 \\ 4 & 27 \% & 2.17 & 0.53-8.91 \\ 3 & (1-7) & 0.97 & 0.91-1.04\end{array}$


Table 1 Characteristics of undocumented migrants and uninsured legal residents $(N=760)$ and determinants of nasal MRSA carriage, in Amsterdam, the Netherlands, October 2018-October 2019 (univariable logistic regression analyses with Firth's correction) (Continued)

\begin{tabular}{|c|c|c|c|c|c|c|c|c|}
\hline \multirow[b]{2}{*}{ Sociodemographic variables } & \multicolumn{2}{|c|}{ Total $(\boldsymbol{N}=760)$} & \multicolumn{2}{|c|}{$\begin{array}{l}\text { MRSA-negative } \\
\text { participants }(\boldsymbol{N}=745)\end{array}$} & \multicolumn{2}{|c|}{$\begin{array}{l}\text { MRSA-positive } \\
\text { participants }(\boldsymbol{N}=15)\end{array}$} & \multicolumn{2}{|c|}{$\begin{array}{l}\text { Univariable } \\
\text { associations }\end{array}$} \\
\hline & $n$ & $\%$ & $n$ & $\%$ & $\bar{N}$ & $\%$ & $\overline{O R}$ & $95 \% \mathrm{Cl}$ \\
\hline Other/unknown & 18 & $2 \%$ & 18 & $2 \%$ & 0 & $0 \%$ & 1.27 & $0.07-22.80$ \\
\hline \multicolumn{9}{|c|}{ Housing situation (multiple answers possible) } \\
\hline Lives in BBB facility & 56 & $7 \%$ & 55 & $7 \%$ & 1 & $7 \%$ & 1.29 & $0.23-7.07$ \\
\hline Lives with friends/family & 401 & $53 \%$ & 394 & $53 \%$ & 7 & $47 \%$ & 0.79 & $0.29-2.12$ \\
\hline Lives in illegal rent & 169 & $22 \%$ & 166 & $22 \%$ & 3 & $20 \%$ & 0.97 & $0.29-3.23$ \\
\hline Lives in housing provided by charity & 64 & $9 \%$ & 63 & $8 \%$ & 1 & $7 \%$ & 1.11 & $0.20-6.09$ \\
\hline Lives on the streets & 60 & $8 \%$ & 59 & $8 \%$ & 1 & $7 \%$ & 1.19 & $0.22-6.55$ \\
\hline Lives in other housing\# & 51 & $7 \%$ & 49 & $7 \%$ & 2 & $13 \%$ & 2.61 & $0.66-10.36$ \\
\hline
\end{tabular}

Number of housemates

No housemates

$<3$

$3-5$

$\geq 6$

Antibiotic use

Current antibiotic use

\section{Recent antibiotic use}

Current or $<3$ months ago

3-6 months ago

$>6$ months ago or never used antibiotics

Does not remember when last using antibiotics

Other potential risk factors

Has been abroad for $>24 \mathrm{~h}$ in the past 6 months

Ever admitted/treated in a foreign hospital

Ever had surgery abroad

Ever received a blood transfusion

No/unknown

Yes

\section{Ever (been) paid for sex}

\begin{tabular}{lllllllll} 
No, never & 613 & $81 \%$ & 600 & $81 \%$ & 13 & $87 \%$ & Ref & \\
Yes, ever paid & 123 & $16 \%$ & 121 & $16 \%$ & 2 & $13 \%$ & 0.92 & $0.23-3.58$ \\
Yes, ever been paid & 24 & $3 \%$ & 24 & $3 \%$ & 0 & $0 \%$ & 0.91 & $0.05-15.72$ \\
Ever injected drugs & 16 & $2 \%$ & 15 & $2 \%$ & 1 & $7 \%$ & 4.88 & $0.84-28.19$ \\
\hline
\end{tabular}

*Insufficient estimation of OR and variance due to ' 0 ' count cell

**Includes family visa and Schengen visa

\#Includes legal rent, housing for asylum seekers, boats, employers, hotels, crisis care, winter care, campers and forest huts

Missing data: region of birth, $n=1$; education, $n=4$; year of leaving country of origin, $n=8$; year of arrival in the Netherlands, $n=6$; way of entering the

Netherlands, $n=7$; number of housemates, $n=13$; current antibiotic use, $n=10$; recent antibiotic use, $n=38$; abroad in past $6 \mathrm{~m}, n=4$; admitted to foreign

hospital, $n=7$

Abbreviations: MRSA methicillin-resistant Staphylococcus aureus, OR odds ratio, Cl confidence interval, IQR inter quartile range, EU European Union, BBB bed bath bread

(2.0, 95\%CI 1.1 to $3.3 \%)$ and uninsured legal residents $(1 / 55)(1.8,95 \% \mathrm{CI} 0.1$ to $9.7 \%)$. The median age of MRSA carriers was 35 years (IQR 32-48) and $73 \%$ $(11 / 15)$ of carriers was male. Table 1 shows the characteristics of MRSA carriers and non-carriers. As shown in Table 1, MRSA carriage was not associated with any sociodemographic variable, migration history or other possible risk factors. 


\section{MRSA genotyping}

Of the 15 isolates from MRSA-positive participants (Table 2), 3 (3/15; 20\%) were Panton-Valentine leukocidin (PVL)-positive. Fourteen different MLVA-types were detected. None of the participants had livestockassociated MRSA. Eleven patients $(11 / 15 ; 73 \%)$ had MLVA-types that have never or rarely been found in both the Amsterdam region and nationwide. Four (4/15; 27\%) participants had MLVA-types that have been regularly (more than 25 times) isolated in other persons outside the Amsterdam region in the Netherlands within one year before participant MRSA strains were isolated. MLVA cluster analysis of the 15 strains obtained in the present study and other strains isolated in the laboratory of the Public Health Service of Amsterdam showed no genetic relationship between strains from participants with one exception (strains 5 and 13, Table 2). A few strains were included in larger clusters consisting of other, previously isolated strains.

\section{Discussion}

In this cross-sectional study among patients attending an NGO health care facility for GP consultations in Amsterdam, the Netherlands, we found a prevalence of $2.0 \%$ for nasal MRSA carriage among undocumented migrants and uninsured legal residents. Prevalence did not differ between the two groups. Sociodemographic characteristics, migration history and other potential risk factors for MRSA were not associated with MRSA carriage. Three participants harbored PVL-positive isolates.

The prevalence of nasal MRSA carriage among undocumented migrants and uninsured legal residents from Amsterdam was higher than that reported for the general Dutch population $(<1 \%)[5,8,9]$. This finding may partly reflect the prevalence of MRSA carriage in the participants' country of origin or in countries through which they travelled in transit to the Netherlands. Another possibility is that MRSA was transmitted between undocumented migrants and uninsured legal residents during their stay in the Netherlands. The fact that 14 different MLVA types were found in the MRSA-positive participants would argue for the former hypothesis. Nevertheless, some MLVA types were also frequently identified in other isolates from inhabitants of the Netherlands (i.e. MT0602, MT0489, MT0491 and MT0321). In addition, we did find other MLVA types (MT0121, MT6237, MT2307 and MT0012) that had not been isolated in other persons belonging to the well-known, worldwide occurring MLVA-complexes MC0005 and MC0008. Nevertheless, MLVA types could represent subtle differences from the MLVA-complexes frequently occurring in the Netherlands and might not be recognizably different. It is unknown from routine surveillance data whether these MLVA types are specifically found in migrants.

A meta-analysis on antimicrobial resistance among migrants in Europe found a pooled $8 \%$ prevalence of

Table 2 Genetic characteristics of MRSA isolates of positive participants ( $N=15)$

\begin{tabular}{|c|c|c|c|c|c|c|}
\hline \multicolumn{7}{|c|}{ MRSA-positive participants $(\boldsymbol{N}=15)$} \\
\hline $\begin{array}{l}\text { Strain } \\
\text { number }\end{array}$ & $\begin{array}{l}\text { MLVA } \\
\text { type }\end{array}$ & $\begin{array}{l}\text { MLVA } \\
\text { complex }\end{array}$ & PVL & $\begin{array}{l}\text { Residing in the } \\
\text { Netherlands } \\
\text { since }\end{array}$ & $\begin{array}{l}\text { Number of times MLVA type was diagnosed in } \\
\text { the Amsterdam region within one year of date } \\
\text { of isolation* }\end{array}$ & $\begin{array}{l}\text { Number of times MLVA type was } \\
\text { diagnosed in the Netherlands within one } \\
\text { year of date of isolation* }\end{array}$ \\
\hline 1 & MT2502 & $\mathrm{NC}$ & positive & 1995 & 1 & 1 \\
\hline 2 & MT0121 & MC0005 & negative & 2018 & 1 & 1 \\
\hline 3 & MT4112 & MC0088 & negative & 2018 & 1 & 1 \\
\hline 4 & MT6237 & $\begin{array}{l}\text { MCO008- } \\
\text { NC }\end{array}$ & negative & 2016 & 1 & 1 \\
\hline 5 & MT0602 & MC0005 & negative & 2016 & 8 & 27 \\
\hline 6 & MT0486 & MC0022 & negative & 2012 & 1 & 11 \\
\hline 7 & MT0489 & MC0254 & negative & 2014 & 16 & 71 \\
\hline 8 & MT2307 & MC0005 & negative & 2018 & 1 & 1 \\
\hline 9 & MT6179 & MC1933 & negative & 2016 & 1 & 2 \\
\hline 10 & МT0491 & MC0022 & negative & 1990 & 16 & 114 \\
\hline 11 & MT2129 & MC0282 & positive & 2018 & 1 & 2 \\
\hline 12 & MT0321 & MC0008 & negative & 2016 & 6 & 35 \\
\hline 13 & MT0602 & MC0005 & negative & 2009 & 2 & 2 \\
\hline 14 & MT0012 & MC0005 & negative & 2016 & 1 & 1 \\
\hline 15 & MT0432 & MC0435 & positive & 2016 & 1 & 1 \\
\hline
\end{tabular}

*Date of isolation refers to the isolation of the MRSA strain from the participant included in this study. This number also includes the strain from the participant Abbreviations: MRSA methicillin-resistant Staphylococcus aureus, PVL Panton-Valentine leukocidin, MLVA Multiple Loci Variable Number Tandem Repeat Analysis, MT MLVA-type, NC nearest complex, MC MLVA-complex 
MRSA carriage [11]. A previous retrospective study analyzing screening cultures from asylum seekers who recently arrived in the Netherlands similarly observed a $6 \%$ prevalence of nasal MRSA carriage [10]. This prevalence would be almost threefold higher compared to that found in our study. Several hypotheses could explain the varying prevalence of MRSA carriage across studies. There could be differences between asylum seekers and undocumented migrants or uninsured legal residents with respect to housing conditions, country of origin or socioeconomic status. Asylum seekers legally entering the Netherlands, as a result of applying for asylum through the centralized application system, are typically accommodated in an asylum center pending their application. Apart from other (indirect) transmission routes, MRSA is known to spread through skin-to-skin contact in places where crowding and contact occur, such as in schools, camps, gyms, prisons, and possibly asylum centers [29]. Alternatively, MRSA could spread during crowded travel to Europe, such as on refugee boats or in tent camps. Nonetheless, a previous report observed 56 different MLVA types among 104 strains harbored among asylum seekers and considering the wide distribution of countries of origin in their study, the presence of MRSA would be more linked to migrants' geographical origin than transmission between asylum seekers [10].

It should be noted that the prevalence of nasal MRSA carriage among rejected asylum seekers in our study (2/ $135=1.5,95 \% \mathrm{CI} 0.2$ to $5.3 \%$ ) was lower than the prevalence of nasal MRSA carriage found in a previous Dutch study of asylum seekers (5.6\%) [10]. Asylum seekers whose applications for asylum have been rejected are probably more likely to have been in the Netherlands longer than those currently seeking asylum. Although the median duration needed to clear MRSA carriage is not well known [30-32], MRSA acquired from their country of origin may have cleared spontaneously in our study population by the time they were screened. Another study has demonstrated that asylum seekers living in the Netherlands for more than $1 \mathrm{y}$ had a lower prevalence of MRSA carriage than recently arrived migrants, thereby providing further evidence for this claim [33]. Yet, at a $5.1 \%$ prevalence in these longer stay migrants, MRSA carriage would still be higher than found in our study or in the general Dutch population.

We did not find any statistically significant risk factors for nasal MRSA carriage, although we did find that individuals with current antibiotic use or ever injecting drug use tended to have a higher prevalence of MRSA carriage. Antibiotic use [34] and injecting drug use [35] are known risk factors for MRSA, in addition to, among others, recent admittance to or treatment in a foreign hospital and working with livestock [6]. We were unable to confirm these latter findings, mainly owing to the lack of power in our study.

In the Netherlands, the MRSA search and destroy policy ensures that high-risk groups for MRSA are actively screened and pre-emptively isolated upon hospital admission [6]. In 2015, the working group on infection prevention (WIP) additionally advised screening individuals who lived in an asylum center in the previous $2 \mathrm{~m}$ for MRSA carriage upon hospital admission [36]. The relatively low MRSA prevalence of $2.0 \%$ found in our study compared to the prevalences found in acknowledged high-risk groups for carriage would suggest that screening undocumented migrants and uninsured legal residents admitted to the hospital would be unjustified. However, notwithstanding the small sample size and limited power to identify significant determinants, studies are needed to confirm our findings.

The main strength of our study is that we included diverse populations that have not yet been considered in previous studies. We were able to reach many, generally hard-to-reach, undocumented migrants and uninsured legal residents of Amsterdam and as the study was conducted in six different languages, a broader geographical range of migrants' country of origin could be included.

However, some limitations need to be addressed. First, as patients were required to have understood one of the six study languages and were taking part in the study with additional HBV, HCV, and HIV screening, the study population was restricted to a convenience sample. Furthermore, Kruispost is a charity-based organization and in order to reduce study costs, we deliberately chose not to have a research associate present for inclusion at all times. The non-random, selective dates of inclusions could have contributed to a lower response. Both the convenience sample and low response might introduce selection bias, which could limit the generalizability of not only all patients at Kruispost, but also of the entire population of undocumented migrants and uninsured legal residents in Amsterdam. Opt-out options were available for MRSA, HBV, HCV and HIV screening; thus the screening for any specific infection was unlikely to influence the attractiveness of this study and reduce the response. Second, over $40 \%$ of patients declined participation and only a small proportion of non-responders completed the short questionnaire on reasons for nonparticipation. Therefore, it is questionable whether the latter proportion is representative of all non-responders. Moreover, based on this small proportion of nonresponders, non-response might be selective. It is unknown to what extent selective non-response and its representativeness for non-responders would have biased our results. Third, more recent migrants were less likely to participate in the study. Since MRSA carriage can spontaneously clear, the prevalence found in our study 
might be an underestimation compared to that from a study including more recent migrants with potentially more recent exposure to MRSA from their home country. Fourth, it was possible that the pattern of missing data was non-monotonic, potentially biasing our results. Most missing data were observed with respect to recent antibiotic use, but we do not know whether missingness was associated with recent antibiotic use. Fifth, we were unable to reach our target of 1000 participants, causing a lower absolute number of participants with MRSA carriage. Therefore, our study has limited power to evaluate determinants of MRSA carriage. Sixth, since we only assessed nasal MRSA carriage, it is possible that patients carrying MRSA in other locations were missed. Patients with current antibiotic use may have also had falsenegative results [37]. These factors could have resulted in an underestimation of the true prevalence of MRSA.

\section{Conclusion}

To the best of our knowledge, this is the first study to examine nasal MRSA carriage among undocumented migrants and uninsured legal residents. Identifying groups with an increased risk of MRSA carriage could lessen the public health consequences of antimicrobialresistant microorganisms in an interconnected world. Bearing the limited study sample in mind, we show that even though our study population has a higher MRSA prevalence than the general Dutch population, the prevalence is lower than that found in many other studies among migrants and asylum seekers. Future studies should confirm the relatively low prevalence of MRSA carriage among undocumented migrants and uninsured legal residents and may explore explanations for differences between this population and asylum seekers.

\section{Supplementary information}

Supplementary information accompanies this paper at https://doi.org/10. 1186/s13756-020-00785-8.

Additional file 1: Supplementary Table 1. Characteristics of included participants $(N=784)$ versus patients who refused participation (but completed a short questionnaire on basic characteristics, $N=195$ ) in Amsterdam, the Netherlands, October 2018-October 2019

Additional file 2: Supplementary Table 2. Reasons for nonparticipation among patients who completed a short questionnaire on basic characteristics $(N=195)$ in Amsterdam, the Netherlands, October 2018-October 2019

\footnotetext{
Abbreviations

CAK: Central Administration Office; CSN: Citizen Service Number; EEA: European Economic Area; EHR: Electronic Health Record; EU: European Union; GP: General practitioner; HBV: Hepatitis B Virus; HCV: Hepatitis C Virus; HIV: Human Immunodeficiency Virus; IQR: Interquartile Range; MLVA: MultiLocus Variable Number Tandem Repeat Analysis; MRSA: Methicillin-resistant Staphylococcus aureus; NVMM: Dutch Society for Medical Microbiology; PVL: Panton-Valentine leukocidin; TB: Tuberculosis; WMO: Medical Research Involving Human Subjects Act
}

\section{Acknowledgements}

The authors would like to thank Freke Zuure for her role in designing the study. Furthermore, we would like to thank all research assistants for their role in collecting the data and Fred Slijkerman for his role in obtaining support from the regional infectious disease control funds. Additionally, the authors thank Leo Schouls (Dutch National Institute for Health and the Environment) for his help in comparing MRSA study isolates with other MRSA isolates from the laboratory of the Public Health Service of Amsterdam. Importantly, we would like to thank all participants for their contribution to our study.

\section{Authors' contributions}

EvD, SK, IJ, MP, AvD, GT and YvD were involved in the conception and design of the study. SK was responsible for the acquisition of data. EvD and $A B$ analyzed and interpreted the data. EvD wrote the manuscript. SK, $A B, I J$, $M P, A v D, G T$ and $Y v D$ were major contributors in revising the manuscript. All authors read and approved the final manuscript.

\section{Funding}

This study was funded by regional infectious disease control funds from the Dutch National Institute for Public Health and the Environment. The funding body had no role in the design of the study and collection, analysis and interpretation of data and in writing the manuscript.

\section{Availability of data and materials}

The data used and/or analyzed during the current study are available from the corresponding author on reasonable request.

\section{Ethics approval and consent to participate}

This study was carried out according to the ethical guidelines of the 1975 Declaration of Helsinki. The medical ethics committee of the Amsterdam University Medical Center (location AMC) decided that the study was beyond the scope of the Medical Research Involving Human Subjects Act (WMO) and therefore does not require institutional review board approval (W18_164). Many undocumented migrants do not feel comfortable with providing their written name or signature on paper and therefore we requested that all participants provide verbal informed consent to participate. All participants were able to withdraw consent to participate in the study at any time without clarification.

\section{Consent for publication}

Not applicable.

\section{Competing interests}

The authors declare that they have no competing interests related to the study.

\section{Author details}

${ }^{1}$ Department of Infectious Diseases, Public Health Service Amsterdam, Nieuwe Achtergracht 100, 1018WT Amsterdam, the Netherlands. ${ }^{2} \mathrm{NGO}$ health care clinic Kruispost, Amsterdam, the Netherlands. ${ }^{3} \mathrm{HIV}$ Monitoring Foundation, Amsterdam, The Netherlands. ${ }^{4}$ Department of Infectious Diseases, Public Health Service Flevoland, Lelystad, the Netherlands. ${ }^{5}$ Division of Infectious Diseases, and Amsterdam Institute for Infection and Immunity (AI\&II), Amsterdam UMC, University of Amsterdam, Department of Internal Medicine, Amsterdam, the Netherlands. ${ }^{6}$ Department of Medical Microbiology, Amsterdam UMC, University of Amsterdam, Amsterdam, the Netherlands.

Received: 21 December 2019 Accepted: 21 July 2020

Published online: 29 July 2020

\section{References}

1. Wertheim HF, Melles DC, Vos MC, van Leeuwen W, van Belkum A, Verbrugh $\mathrm{HA}$, et al. The role of nasal carriage in Staphylococcus aureus infections. Lancet Infect Dis. 2005:5(12):751-62.

2. Cassini A, Hogberg LD, Plachouras D, Quattrocchi A, Hoxha A, Simonsen GS, et al. Attributable deaths and disability-adjusted life-years caused by infections with antibiotic-resistant bacteria in the EU and the European economic area in 2015: a population-level modelling analysis. Lancet Infect Dis. 2019;19(1):56-66. 
3. Wertheim HF, Vos MC, Ott A, van Belkum A, Voss A, Kluytmans JA, et al. Risk and outcome of nosocomial Staphylococcus aureus bacteraemia in nasal carriers versus non-carriers. Lancet. 2004;364(9435):703-5.

4. von Eiff C, Becker K, Machka K, Stammer H, Peters G. Nasal carriage as a source of Staphylococcus aureus bacteremia. Study Group N Engl J Med. 2001:344(1):11-6.

5. Wertheim HF, Vos MC, Boelens HA, Voss A, Vandenbroucke-Grauls CM, Meester MH, et al. Low prevalence of methicillin-resistant Staphylococcus aureus (MRSA) at hospital admission in the Netherlands: the value of search and destroy and restrictive antibiotic use. J Hosp Infect. 2004;56(4):321-5.

6. Guideline on methicillin-resistant Staphylococcus aureus (MRSA). Dutch Working Group Infection Prevention (WIP) 2012.

7. Brauer R, Ruigomez A, Downey G, Bate A, Garcia Rodriguez LA, Huerta C, et al. Prevalence of antibiotic use: a comparison across various European health care data sources. Pharmacoepidemiol Drug Saf. 2016;25(Suppl 1): $11-20$.

8. Bode LG, Wertheim HF, Kluytmans JA, Bogaers-Hofman D, VandenbrouckeGrauls CM, Roosendaal R, et al. Sustained low prevalence of meticillinresistant Staphylococcus aureus upon admission to hospital in the Netherlands. J Hosp Infect. 2011;79(3):198-201.

9. Weterings $\mathrm{V}$, Veenemans J, van Rijen M, Kluytmans J. Prevalence of nasal carriage of methicillin-resistant Staphylococcus aureus in patients at hospital admission in the Netherlands, 2010-2017: an observational study. Clin Microbiol Infect. 2019.

10. Ravensbergen SJ, Berends M, Stienstra Y, Ott A. High prevalence of MRSA and ESBL among asylum seekers in the Netherlands. PLoS One. 2017;12(4): e0176481.

11. Nellums LB, Thompson H, Holmes A, Castro-Sanchez E, Otter JA, Norredam $M$, et al. Antimicrobial resistance among migrants in Europe: a systematic review and meta-analysis. Lancet Infect Dis. 2018;18(7):796-811.

12. Danielsen AS, Elstrom P, Arnesen TM, Gopinathan U, Kacelnik O. Targeting TB or MRSA in Norwegian municipalities during 'the refugee crisis' of 2015 a framework for priority setting in screening. Euro Surveill. 2019;24(38).

13. Aro T, Kantele A. High rates of meticillin-resistant Staphylococcus aureus among asylum seekers and refugees admitted to Helsinki University Hospital, 2010 to 2017. Euro Surveill. 2018:23(45).

14. Johnston V. Australian asylum policies: have they violated the right to health of asylum seekers? Aust N Z J Public Health. 2009:33(1):40-6.

15. Steel Z, Liddell BJ, Bateman-Steel CR, Zwi AB. Global protection and the health impact of migration interception. PLoS Med. 2011:8(6):e1001038.

16. Hacker K, Chu J, Leung C, Marra R, Pirie A, Brahimi M, et al. The impact of immigration and customs enforcement on immigrant health: perceptions of immigrants in Everett, Massachusetts, USA. Soc Sci Med. 2011;73(4):586-94.

17. Schanzer B, Dominguez B, Shrout PE, Caton CL. Homelessness, health status, and health care use. Am J Public Health. 2007;97(3):464-9.

18. Badiaga S, Raoult D, Brouqui P. Preventing and controlling emerging and reemerging transmissible diseases in the homeless. Emerg Infect Dis. 2008; 14(9):1353-9.

19. Coppola N, Alessio L, Gualdieri L, Pisaturo M, Sagnelli C, Caprio N, et al. Hepatitis B virus, hepatitis $C$ virus and human immunodeficiency virus infection in undocumented migrants and refugees in southern Italy, January 2012 to June 2013. Euro Surveill. 2015;20(35).

20. Coppola N, Alessio L, Gualdieri L, Pisaturo M, Sagnelli C, Minchini C, et al. Hepatitis $B$ virus infection in undocumented immigrants and refugees in southern Italy: demographic, virological, and clinical features. Infect Dis Poverty. 2017;6.

21. El-Hamad I, Pezzoli MC, Chiari E, Scarcella C, Vassallo F, Puoti M, et al. Pointof-care screening, prevalence, and risk factors for hepatitis B infection among 3,728 mainly undocumented migrants from non-EU countries in northern Italy. J Travel Med. 2015;22(2):78-86.

22. van de Sande JSO, van den Muijsenbergh M. Undocumented and documented migrants with chronic diseases in family practice in the Netherlands. Fam Pract. 2017;34(6):649-55.

23. Schoevers MA, van den Muijsenbergh ME, Lagro-Janssen AL. Self-rated health and health problems of undocumented immigrant women in the Netherlands: a descriptive study. J Public Health Policy. 2009;30(4):409-22.

24. Kluytmans-van den Bergh MF, Vos MC, Diederen BM, Vandenbroucke-Grauls CM, Voss A, Kluytmans JA, et al. Dutch guideline on the laboratory detection of methicillin-resistant Staphylococcus aureus. Eur J Clin Microbiol Infect Dis. 2014:33(1):89-101.
25. Kilic A, Muldrew KL, Tang YW, Basustaoglu AC. Triplex real-time polymerase chain reaction assay for simultaneous detection of Staphylococcus aureus and coagulase-negative staphylococci and determination of methicillin resistance directly from positive blood culture bottles. Diagn Microbiol Infect Dis. 2010;66(4):349-55.

26. Lina G, Piemont Y, Godail-Gamot F, Bes M, Peter MO, Gauduchon V, et al. Involvement of Panton-valentine leukocidin-producing Staphylococcus aureus in primary skin infections and pneumonia. Clin Infect Dis. 1999;29(5): $1128-32$.

27. Boyle-Vavra S, Daum RS. Community-acquired methicillin-resistant Staphylococcus aureus: the role of Panton-valentine leukocidin. Lab Investig. 2007;87(1):3-9.

28. Schouls LM, Spalburg EC, van Luit M, Huijsdens XW, Pluister GN, van Santen-Verheuvel MG, et al. Multiple-locus variable number tandem repeat analysis of Staphylococcus aureus: comparison with pulsed-field gel electrophoresis and spa-typing. PLoS One. 2009;4(4):e5082.

29. Vieira MT, Marlow MA, Aguiar-Alves F, Pinheiro MG, Freitas Alves Mde F, Santos Cruz ML, et al. Living conditions as a driving factor in persistent methicillin-resistant Staphylococcus aureus colonization among HIV-infected youth. Pediatr Infect Dis J. 2016;35(10):1126-31.

30. Larsson AK, Gustafsson E, Nilsson AC, Odenholt I, Ringberg H, Melander E. Duration of methicillin-resistant Staphylococcus aureus colonization after diagnosis: a four-year experience from southern Sweden. Scand J Infect Dis. 2011;43(6-7):456-62.

31. Robicsek A, Beaumont JL, Peterson LR. Duration of colonization with methicillin-resistant Staphylococcus aureus. Clin Infect Dis. 2009:48(7):910-3.

32. Scanvic A, Denic L, Gaillon S, Giry P, Andremont A, Lucet JC. Duration of colonization by methicillin-resistant Staphylococcus aureus after hospital discharge and risk factors for prolonged carriage. Clin Infect Dis. 2001;32(10): 1393-8.

33. Ravensbergen SJ, Louka C, Ott A, Rossen JW, Cornish D, Pournaras S, et al. Proportion of asylum seekers carrying multi-drug resistant microorganisms is persistently increased after arrival in the Netherlands. Antimicrob Resist Infect Control. 2019;8:6.

34. Lekkerkerk WSN, Haenen A, van der Sande MAB, Leenstra T, de Greeff S, Timen A, et al. Newly identified risk factors for MRSA carriage in the Netherlands. PLoS One. 2017;12(11):e0188502

35. El-Sharif A, Ashour HM. Community-acquired methicillin-resistant Staphylococcus aureus (CA-MRSA) colonization and infection in intravenous and inhalational opiate drug abusers. Exp Biol Med (Maywood). 2008;233(7): 874-80.

36. Mascini EH, Vos R, Cohen Stuart, JG. Alertness warranted for possible risk of MRSA carriage among asylum seekers: Duth Working Group on Infection Prevention; 2015 [Available from: https:/www.rivm.nl/sites/default/files/201 8-11/Correctie\%20-\%20Alertheid\%20gevraagd\%20voor\%20mogelijk\%2 Orisico\%20van\%20MRSA.pdf..

37. Dangerfield B, Chung A, Webb B, Seville MT. Predictive value of methicillinresistant Staphylococcus aureus (MRSA) nasal swab PCR assay for MRSA pneumonia. Antimicrob Agents Chemother. 2014;58(2):859-64.

\section{Publisher's Note}

Springer Nature remains neutral with regard to jurisdictional claims in published maps and institutional affiliations.

Ready to submit your research? Choose BMC and benefit from:

- fast, convenient online submission

- thorough peer review by experienced researchers in your field

- rapid publication on acceptance

- support for research data, including large and complex data types

- gold Open Access which fosters wider collaboration and increased citations

- maximum visibility for your research: over $100 \mathrm{M}$ website views per year

At $\mathrm{BMC}$, research is always in progress.

Learn more biomedcentral.com/submissions 